\title{
Clostridium Colitis
}

National Cancer Institute

\section{Source}

National Cancer Institute. Clostridium Colitis. NCI Thesaurus. Code C36067.

An acute inflammatory disorder of the colon secondary to infection with any species of the bacterial genus Clostridium. Symptoms include acute diarrhea, abdominal pain, and myalgia. 